\title{
Cost benefit analysis of Haemophilus influenzae type $b$ vaccination programme in Israel
}

\author{
Gary M Ginsberg, Imad Kassis, Ron Dagan
}

\begin{abstract}
Study objective-The recent availability of Haemophilus influenzae type b (HIB) conjugate vaccines prompted an examination of the costs and benefits of four and three dose HIB prevention programmes targeting all newborns in Israel.

Measurements and main results-A four dose programme would reduce the number of childhood (aged 0-13) HIB cases from $184 \cdot 2$ to $31 \cdot 3$ per year, yielding a benefit $(\$ 1.03$ million) to cost ( $\$ 3.55$ million) ratio of just $0 \cdot 29 / 1$ for health services only, based on a vaccine price of $\$ 7 \cdot 74$ per dose. When benefits resulting from a reduction in mild handicaps and severe neurological sequelae are included, the benefit ( $\$ 4.48$ million) to cost ratio rises to $1 \cdot 26 / 1$ and it reaches $1 \cdot 45 / 1$ when the $\$ 0.66$ million indirect benefits of reduced work absences and mortality are also included. Break even vaccine costs are $\$ 2 \cdot 24$ when health service benefits only are considered and $\$ 11 \cdot 21$ when all the benefits are included.

Conclusion-In the absence of other projects with higher benefit to cost ratios, Israel should start to provide a nationwide HIB vaccination programme since the monetary benefits to society of such a programme will exceed the costs to society. A barrier to implementation may occur, however, because the costs of the programme exceed the benefits to the health services alone.
\end{abstract}

f Epidemiol Community Health 1993; 47: 485-490

Department of Data Analysis, Division of Computing and Information, Ministry of Health and Hebrew University-Hadassah School of Public Health, Jerusalem, Israel

G M Ginsberg

Paediatric Infectious

Disease Unit, Soroka University Medical

Centre, PO Box 151,

Faculty of Health

Sciences, Ben-Gurion

University of the

Negev, Beer-Sheva,

Israel

I Kassis

R Dagan

Correspondence to:

Dr G M Ginsberg, Reuven 25/2, Baka, Jerusalem 93510 , Israel pneumonia, sepsis, and cellulitis also occur. ${ }^{1}$ In Israel, cases of HIB associated with epiglottitis are relatively rare events. ${ }^{1}$

The recent collaborative study in Israel $^{1}$ collected data from HIB patients (with positive blood or CSF culture) who received care in emergency rooms of hospitals or were admitted to hospital pediatric departments. The study found that the duration of hospital stay ranged from 0 days (for those who only received care in the emergency room) to 90 days. The overall mean (SD) stay was $11.8(8 \cdot 7)$ days, with $64 \%$ of cases spending $\geqslant 10$ days in hospital. Cases with meningitis spent a mean (SD) of $14 \cdot 1(6 \cdot 6)$ days in hospital and $93 \%$ were there for $\geqslant 10$ days.

The clinical efficacy of existing conjugate HIB programmes starting with children aged $2,{ }^{3-5} 3,^{6}$ and 4 months ${ }^{48}$ has been established in the USA and Finland. In Israel, the public has become aware of such a vaccine through various media sources and has to some extent decided to purchase the vaccines on the free market from pharmacists. In some cases, vaccines are purchased for children well over the "danger" age for HIB infections; $93 \%$ and $98 \%$ of cases occurring in children under 2 years and 5 years old respectively. ${ }^{1}$ In March 1992, the Israel Pediatric Association recommended HIB vaccination of all children between the ages of 2 and 23 months. Licencing and recommendations alone, however, are unlikely to have a major impact on the disease incidence in the community. ${ }^{9}$

Israel has a strong public health tradition via its network of family health centres. In the past three years, the Infectious Disease Committee of the Ministry of Health, aided by information from ex-ante cost-benefit analyses, have added nationwide vaccinations against hepatitis $B$ for newborns ${ }^{10}$ and a second measles vaccination for schoolchildren ${ }^{11}$ to the traditional diphtheria, tetanus, and pertussis (DTP); polio; and measles, mumps, and rubella (MMR) vaccination schedules.

Cost-benefit studies of HIB vaccination programmes have been undertaken in the USA. These analyses, however, were based on single dose inoculation of children aged 18 or 24 months old. ${ }^{12-14}$ To help decide whether HIB vaccinations should be provided via the public health services in Israel, this paper provides a cost-benefit analysis of a nationwide four or three dose HIB immunisation programme in which conjugate vaccine is given to children at $2,4,6$, and 15 months, or 2,4 , and 12 months of age.

\section{Methods}

Demographic, epidemiological (HIB age specific incidence and transitory probabilities of handicaps 
and severe neurological sequelae), health service (type and amount of care required for HIB cases), and economic (costs of innoculation, costs of caring for HIB cases and vaccinating contacts, labour force participation rates) data were entered into a computerised spreadsheet model.

The basic formula used is as follows:

Benefit to cost ratio=benefits of programme/costs of programme, where-

Cost of programme $=$ costs of vaccine

+additional labour costs of giving innoculation

training and health education costs

+ transportation costs of vaccine and nurses

+cold-chain costs

+ costs of adverse reactions.

Benefits of programme $=$ costs of HIB without vaccination programme

-costs of HIB vaccination programme.

where the costs of HIB include costs of ambulatory care, emergency room care, hospitalisation, as well as costs of prophylatic antibiotic treatments for contacts at home or in day-care situations. The costs also include costs of special education for children handicapped as a result of HIB and long term care costs for those with severe neurological sequelae.

Three different benefit to cost ratios were calculated using a discounted cash flow of $5 \cdot 0 \%$ a year.

(i) The direct "health services" benefit to cost ratio, which includes only costs and benefits relating to health services (for example, costs of vaccine, ambulatory care, hospital stay, etc).

(ii) The direct "wellfare services" benefit to cost ratio, which includes only those costs and benefits relating to health services and the ministeries of education (special education costs), labour and welfare (long term care for severe neurological sequelae).

(iii) The total "social" benefit to cost ratio (that is, to society as a whole). This includes the direct welfare services costs and benefits in addition to indirect benefits related to the reductions in parental time off work caring for their children and reductions in mortality which will be achieved by implementing the programme.

\section{Results}

COST OF VACCINATION PROGRAMMES

Table I lists the unit and total costs of programmes aiming to provide four pediatric doses of conjugate type HIB vaccine to the estimated 100000 in an annual birth cohort. The total cost of a four dose programme is $\$ 3.55$ million based on a unit cost of $\$ 7.74$ per dose. This was somewhat pessimistically estimated as being $50 \%$ higher than the federal contract prices in the USA, ${ }^{15}$ since the Ministry of Health in Israel has far less bargaining

Table I HIB vaccine costs for the one year cohort

\begin{tabular}{|c|c|c|c|c|c|c|}
\hline & \multicolumn{2}{|c|}{ Unit cost (\$) } & \multirow{2}{*}{$\frac{\text { No }}{4 \text { doses }}$} & \multirow{2}{*}{$\frac{\text { No }}{3 \text { doses }}$} & \multicolumn{2}{|c|}{ Total cost (\$) } \\
\hline & $\overline{4 \text { doses }}$ & 3 doses & & & 4 doses & 3 doses \\
\hline Vacci & $\overline{7 \cdot 74}$ & $12 \cdot 38$ & 415360 & $\overline{311} \overline{520}$ & 3214886 & 3855060 \\
\hline Swab & 0.0083 & 0.0083 & 352000 & 264000 & 2922 & 2191 \\
\hline Disposable syringe & 0.0434 & 0.0434 & 352000 & 264000 & 15277 & 11458 \\
\hline Needle & 0.0062 & 0.0062 & 352000 & 264000 & 2182 & 1637 \\
\hline $\mathrm{Lab}$ & $8 \cdot 00$ & $8 \cdot 00$ & 29333 & 22000 & 234667 & 176000 \\
\hline Side & 0.00 & 0.00 & 352000 & 264000 & 0 & 0 \\
\hline Health education & $0 \cdot 80$ & $0 \cdot 80$ & 100000 & 100000 & 80000 & 80000 \\
\hline
\end{tabular}

power with the pharmaceutical companies because of Israel's far lower absolute number of annual births. The total cost includes a provision of $18 \%$ for vaccine wastage ${ }^{16}$ and a compliance rate of $88 \%{ }^{17}$ based on compliance with the DTP immunisation schedule in Israel.

Since the HIB immunisation would be administered within the current DTP ${ }^{18}$ and MMR at 15 months innoculation schedules in mother and child health clinics, we assumed the following: an estimate of only five minutes extra public health nurses' time per vaccination (costing $\$ 8.00$ per hour); no extra parental time off work; no extra transportation costs of the inoculated persons or their parents; and no extra-marginal costs resulting from short term vaccination side effects. The vaccine has not been shown to be associated with any serious or long term sequelae. ${ }^{7}{ }^{18}$ It is envisaged that the present cold-chain capacity is sufficient to handle an increased annual load of around 300 000-400 000 vaccine doses nationally (personal comunication, Dr Matas, National Public Health Laboratories).

An allocation of $\$ 0.80$ per targeted person per annum was estimated for additional health education and training $\operatorname{costs}^{19}$ relating to the HIB vaccine. The health education component will be aimed at raising compliance levels through public service media broadcasts. The training component will be aimed at increasing the public health nurses ability to explain to parents and children the reasons for HIB immunization and also the nurses own awareness of the importance of following an amended immunization schedule that includes HIB.

COSTS OF TREATING HIB (table II)

The total costs of $\$ 32183$ per case comprised the following elements:

\section{Hospital admission}

We assumed that $75 \%$ of cases had a 15 minute ambulatory care visit (costing \$4.67) before arriving at the hospital and that all cases had a 15 minute follow up visit after discharge from hospital, also costing $\$ 4 \cdot 67$. Hospital stay costs for HIB were obtained by costing the treatments recorded in the case notes of a sample of "easy, moderate, and severe" cases of HIB treated at the Soroka Medical Centre. The costs of laboratory tests were obtained from the Ministry of Health pricing lists and the costs of pharmaceutical supplies from the chief pharmacist of a large Jerusalem teaching hospital (Alan Greenberg, personal communication 1992). Based on an average length of stay of 11.8 days, the average cost per case admitted to hospital was $\$ 6424$. This figure included ambulatory and outpatient visits costing $\$ 8$ and emergency room costs of $\$ 433$. Hospital staff costs were based on the average cost of treatment in pediatric intensive care units and pediatric departments of $\$ 805$ and $\$ 259$ per day respectively for medical care, tests, and drugs, which included a general overhead of $46.84 \%$ and $35 \cdot 14 \%$ respectively ${ }^{20}$ for cleaning, laundry and food, maintenance, heating, electricity, administration, depreciation, etc. Additional costs were also incurred through parents taking time off work to care for their child in hospital, based on mothers needing to be with their children for $20 \cdot 8$ 
Table II Costs per case of HIB

\begin{tabular}{lllllc}
\hline & $\begin{array}{l}\text { Direct costs } \\
\text { costs }(\boldsymbol{S})\end{array}$ & $\begin{array}{l}\text { Long term } \\
\text { care }(\boldsymbol{S})\end{array}$ & Work $(\boldsymbol{S})$ & Death $(\boldsymbol{S})$ & Total $(\boldsymbol{S})$ \\
\hline Deaths & 0 & 0 & 0 & 4166 & 4166 \\
Hospital & 6424 & 0 & $265^{\star}$ & 0 & 6689 \\
Special education & 0 & 11958 & 0 & 0 & 11958 \\
Severe neurological & 0 & 11059 & 0 & 0 & 11059 \\
Contacts & 416 & 0 & $12 \dagger$ & 0 & 427 \\
Total & 6840 & 23018 & 277 & 4165 & 34300 \\
\hline
\end{tabular}

*Includes $\$ 6.31$ for travel costs of parents for ambulatory visits.

*Includes $\$ 6.31$ for travel costs of parents for ambulatory visits.
tIncludes $\$ 4.87$ for travel costs of parents for prophlyactic care.

days per case (including two days before hospital admission and seven days after discharge). After adjustment for the 5.5 day working week in Israel, annual holidays, and the female labour force participation rates of $42.3 \%$ (for those with children under a year old) and $63.7 \%$ (for those with children aged 1-5 years old), it is estimated that 6.81 net working days were lost at a cost of $\$ 37.98$ per day, ${ }^{17}$ costing $\$ 259$ per case. Finally, additional travelling costs of around $\$ 6$ were incurred by the parents taking $75 \%$ of the children for pre- and all of the children for a posthospitalisation ambulatory visits, each visit costing around $\$ 4.67$ in physicians and medical secretary's wages.

\section{Mortality}

Mortality costs of $\$ 225218$ per deceased, or $\$ 4165$ per case based on the $2.03 \%$ case fatality rate, ${ }^{1}$ were estimated for HIB deaths at a mean age of 1 year old, using the gross national product (GNP) per head method of valuing life, which assigns an equal value to everyone in society equivalent to the GNP per head of the population $^{21}$ of $\$ 10989$ in 1991. ${ }^{17}$ Every child, irrespective of gender and whether they would have been a doctor, musician, farmer, unemployed, student or housewife received the same valuation, based on discounting the value of the deceased's 76.4 expected years of life lost ${ }^{17}$ at the average case age of 13.8 months old.

\section{Special education}

We assumed that $13.4 \%$ of children would require special education because of HIB infection, based on Taylor's study ${ }^{22}$ which found that $26.8 \%$ of children who had HIB needed special education compared with $13.4 \%$ of a control group who had not contracted HIB. Special education costs amount to $\$ 11958$ per case of HIB, based on discounted costs of $\$ 89228$ per person requiring special education, under the assumption that each person requires special care for 16 years at a cost of $\$ 7841$ per annum in excess of the costs of normal education. ${ }^{23}$

\section{Severe neurological sequelae}

We assumed that $7 \%$ of survivors of an HIB meningitis episode $(3.67 \%$ of all HIB cases in Israel) have severe long term neurological sequelae requiring long term care..$^{24 \cdot 28}$ Costs of caring for children with severe neurological

Table III HIB incidence by vaccination status in cohort of 100000 babies

\begin{tabular}{|c|c|c|c|c|c|c|c|}
\hline \multirow[b]{2}{*}{ Status } & \multicolumn{4}{|l|}{ Age (v) } & \multirow[b]{2}{*}{3} & \multirow[b]{2}{*}{4} & \multirow[b]{2}{*}{$5-13$} \\
\hline & $0-1.3$ & 0 & 1 & 2 & & & \\
\hline No vaccination & $184 \cdot 20$ & $128 \cdot 70$ & $45 \cdot 10$ & 5.50 & $2 \cdot 20$ & $2 \cdot 20$ & 0.50 \\
\hline 3 Dose vaccination & $37 \cdot 27$ & $30 \cdot 23$ & $5 \cdot 41$ & 0.66 & $0 \cdot 26$ & $0 \cdot 26$ & 0.45 \\
\hline Reduction & 146.93 & $98 \cdot 47$ & $39 \cdot 69$ & $4 \cdot 84$ & 1.94 & 1.94 & 0.05 \\
\hline 4 Dose vaccination & $31 \cdot 33$ & $24 \cdot 29$ & $5 \cdot 41$ & 0.66 & $0 \cdot 26$ & $0 \cdot 26$ & 0.45 \\
\hline Reduction & $152 \cdot 87$ & $104 \cdot 41$ & $39 \cdot 69$ & $4 \cdot 84$ & 1.94 & 1.94 & 0.05 \\
\hline
\end{tabular}

sequelae amount to $\$ 11059$ per case of HIB, based on discounted costs of $\$ 300801$ per case with severe neurological sequelae, assuming that each case requires special care for the rest of his or her lifetime at a cost of $\$ 14764$ per year. ${ }^{23}$

\section{Following up contacts}

The current practice in Israel is to provide antibiotic prophylaxis to the household and child care contacts of HIB cases, who are at considerably higher risk of contracting HIB than the general population. ${ }^{29}{ }^{30}$ Prophylactic treatment is based on each contact taking a four day course of Rifampin in doses of $20 \mathrm{mg} / \mathrm{kg}$ to children, with a $600 \mathrm{mg}$ limit per dose.

Based on records in the Jerusalem district for 1991 and 1992 (Anita Bashai, nurse epidemiologist, personal communication, 1992), each case has on average 2.79 adult contacts (immediate family plus child minder in $36 \%$ of the cases) and $5 \cdot 50$ child contacts (immediate family plus $9 \cdot 8$ day care contacts in $36 \%$ of the cases). In about $90 \%$ of cases, the parents of the HIB child visit the district health office to receive the Rifampin for all their household members. Conversely, in $90 \%$ of all cases (all districts except Jerusalem) the district health nurse visited the day care centre in order to explain the situation to the child minder and parents of the children and to distribute the Refampin. In addition, each case generated about five telephone queries of 10 minutes duration from concerned neighbours for advice from the public health nurse.

Total contact costs per case amount to $\$ 427$, including $\$ 376$ for rifampin, $\$ 32$ for the 4.04 hours of nurses' time required (at $\$ 8.00$ per hour), $\$ 8$ for nurses' travel costs, $\$ 7$ for parents and child minders for time off work and $\$ 5$ for their travelling costs to the district health office.

\section{TOTAL BENEFITS}

We assumed a vaccine efficacy of $26 \%, 97 \%$, $100 \%$, and $100 \%$ for the four conjugate doses given at 2, 4, 6, and 15 months respectively based on trials in the USA $^{3}$ and Finland. ${ }^{7}$ We also assumed a compliance rate of $88 \%$ with the programme ${ }^{17}$ and that vaccine protection would last for five years, ${ }^{6}{ }^{31}$ although it is possible that the vaccine efficacy could be even greater. We assumed there would be no reported vaccine associated cases since no increased incidence of HIB has been found during the first two weeks after immunization with HbOC. ${ }^{518} 32$

We assumed conservatively that the true national incidence rate of HIB is $10 \%$ higher than the rates found in Dagan's study, ${ }^{1}$ since for some HIB patients blood cultures were either lost, negative, or were not obtained.

The implementation of a nationwide vaccination policy, with children receiving vaccinations at average age of $2 \cdot 5,4 \cdot 5,6 \cdot 5$, and $15 \cdot 5$ months, based on estimates of the true age-specific incidence rates of HIB, would reduce the number of HIB cases in the cohort's lifetime from around $184 \cdot 2$ to $31 \cdot 3$ cases (table III).

The treatment modality costs per case (table II) were then multiplied by the estimated age-specific cohort incidence of HIB (table III), using a discount rate of $5.0 \%$. If a four dose vaccination policy is adopted, treatment costs will fall by 
Table IV Benefits of HIB vaccination programme for 100000 babies

\begin{tabular}{|c|c|c|c|c|c|}
\hline & \multicolumn{3}{|c|}{ Treatment costs $(\$)$} & \multicolumn{2}{|c|}{ Treatment costs (\$) } \\
\hline & $\begin{array}{l}\text { No } \\
\text { vaccination }\end{array}$ & $\begin{array}{l}4 \text { dose } \\
\text { vaccination }\end{array}$ & Benefits & $\begin{array}{l}3 \text { dose } \\
\text { iaccination }\end{array}$ & Benefits \\
\hline Direct & 1235829 & 210581 & 1025248 & 251213 & 984616 \\
\hline Long term & 4159030 & 708685 & 3450345 & 845426 & 3313604 \\
\hline Work & 49974 & 8515 & 41458 & 10158 & 39815 \\
\hline Mortality & 752808 & 128276 & 624532 & 153027 & 599781 \\
\hline Total & 6197640 & 1056058 & 5141582 & 1259824 & 4937816 \\
\hline
\end{tabular}

$83.0 \%$ from $\$ 6.20$ million to $\$ 1.06$ million (table IV), a saving of $\$ 5 \cdot 14$ million, giving a social benefit to cost ( $\$ 3.55$ million) ratio of $1.45 / 1$ (table V). When welfare services only are considered, benefits ( $\$ 4.48$ million) still exceed costs by a $1 \cdot 26 / 1$ ratio. Direct health service benefits amount only to $\$ 1.03$ million, giving a health service benefit to cost ratio of only $0 \cdot 29 / 1$, that is costs are over three times greater than benefits

The net costs to the health services only, per case of HIB prevented, per life year saved, and per life saved are $\$ 16516, \$ 11382$, and $\$ 869200$ under the four dose regimen.

Table VI shows that the benefit to cost ratios, assuming a $95 \%$ efficiency rate for antibiotic prophylaxis of contacts of HIB cases, range from as low as $0.08 / 1$ for a secondary attack rate of $0 \cdot 10 \%{ }^{32}$ to $1 \cdot 56 / 1$ for a secondary attack rate of $2 \cdot 00 \%$.

\section{Discussion}

A four dose programme that aims to vaccinate all children at ages $2,4,6$, and 12 months, will reduced the incidence of HIB in an annual cohort of 100000 persons from $184 \cdot 2$ to $31 \cdot 3$ cases (table III). The number of HIB cases requiring special education as a result of sequelae would fall from $24 \cdot 7$ to $4 \cdot 2$, and the number of cases requiring long term neurological care would decrease from $6 \cdot 8$ to $1 \cdot 2$ cases. Mortality associated with HIB would decrease from 3.4 to 0.58 cases in an annual cohort of newborns.

The $\$ 3.55$ million costs of such a programme (at a vaccine cost of $\$ 7 \cdot 74$ per dose), are exceeded by the benefits from the reduction in morbidity to the welfare services ( $\$ 4.48$ million) or to society as a whole ( $\$ 5 \cdot 14$ million). However, the costs of the programme are over three times as large as the benefits to just the health services alone $(\$ 1.03$ million).

The biggest component of costs per case was that of special education and care for long term severe neurological sequelae, accounting for around $67 \cdot 1 \%$ of the $\$ 34300$ costs per case. Previous cost-benefit studies of HIB in the USA show considerable variation in estimating special education costs and care costs for persons with severe neurological sequelae. ${ }^{12}{ }^{14}$ Even if we have underestimated these long term care costs by $30 \%$, benefits still exceed costs, with a social benefit to cost ratio of $1 \cdot 16 / 1$. Variation of other parameters (except for vaccine costs and discount rates) had little impact on the benefit to cost ratios.

If HIB vaccine is provided as a "cocktail" with DPT or MMR in the same syringe, the extramarginal labour, syringe, needle, and swab costs of the programme would approach zero, reducing total costs to $\$ 3.29$ million, giving a benefit to cost ratio of $1 \cdot 56 / 1$.

If the Ministry of Health manages to negotiate a four dose vaccine price equivalent to the $\$ 5 \cdot 16$ paid by federal contract in the USA, ${ }^{15}$ the benefit to cost ratios to society, welfare, and the health services will rise to $2 \cdot 04 / 1,1.76 / 1$, and $0.43 / 1$ respectively.

Assuming a vaccine cost of $\$ 12.38$ per dose (also $50 \%$ higher than the federal contract costs in the USA $)^{15}$ a three dose regimen using PRP type vaccines given at ages 2,4 , and 12 months and with vaccine efficacy of $60 \%, 89.3 \%$, and $100 \cdot 0 \%,{ }^{4} 57333.4$ would cost $\$ 0.58$ million more (table I) and would prevent only six more cases (table III) than the four dose regimen. The total costs of $\$ 4.13$ million exceed the benefits from the reduction in morbidity to the health services ( $\$ 0.98$ million), but are exceeded by the benefits to the welfare services ( $\$ 4.30$ million) or to society as a whole ( $\$ 4.93$ million). Any relative advantage in cost effectiveness of the four dose regimen over a three dose regimen depends almost entirely on the cost per dose differential, since the efficacy of both regimens is similar. ${ }^{6} 35$

When we reduced the annual discount rate to $2.5 \%$, the "social" benefit to cost ratios rose to
Table $V$ Sensitivity analysis: benefit to cost ratios

\begin{tabular}{|c|c|c|c|c|c|c|c|c|c|c|}
\hline & 4 dose se & Iule & & & & 3 doses & ulc & & & \\
\hline $\begin{array}{l}\text { Cost } \\
\text { per dose }\end{array}$ & $\begin{array}{l}\text { Health } \\
\text { services } \\
\text { only }\end{array}$ & $\begin{array}{l}\text { Health } \\
\text { services } \\
\text { plus } \\
\text { sequelae }\end{array}$ & Society & $\begin{array}{l}\text { Society } \\
\text { minus } \\
30 \%\end{array}$ & $\begin{array}{l}\text { Society } \\
\text { plus } \\
30 \%\end{array}$ & $\begin{array}{l}\text { Health } \\
\text { services } \\
\text { only }\end{array}$ & $\begin{array}{l}\text { Health } \\
\text { services } \\
\text { plus } \\
\text { sequelae }\end{array}$ & Society & $\begin{array}{l}\text { Society } \\
\text { minus } 30 \% \\
\text { sequelac }\end{array}$ & $\begin{array}{l}\text { Society } \\
\text { plus } 30 \% \\
\text { scquclac }\end{array}$ \\
\hline$\$ 1.00$ & $2 \cdot 24$ & $9 \cdot 76$ & $11 \cdot 21$ & 8.95 & $13 \cdot 47$ & 2.95 & 12.89 & $1 \overline{4 \cdot 81}$ & 11.83 & $\overline{17} \cdot 79$ \\
\hline$\$ 2.00$ & $1 \cdot 12$ & $4 \cdot 88$ & 5.61 & $4 \cdot 48$ & 6.73 & $1 \cdot 48$ & 6.45 & $7 \cdot 40$ & 5.91 & 8.89 \\
\hline $\begin{array}{l}\$ 2.24 \\
\$ 2.95\end{array}$ & $1 \cdot 00$ & & & & & & & & & \\
\hline $\begin{array}{l}\$ 2.95 \\
\$ 3.00\end{array}$ & & & & & & 1.00 & & & & \\
\hline$\$ 3.00$ & 0.75 & 3.25 & 3.74 & $2 \cdot 98$ & $4 \cdot 49$ & 0.98 & $4 \cdot 30$ & 4.94 & 3.94 & 5.93 \\
\hline$\$ 4.00$ & 0.56 & $2 \cdot 44$ & $2 \cdot 80$ & $2 \cdot 24$ & 3.37 & $0 \cdot 74$ & $3 \cdot 22$ & $3 \cdot 70$ & 2.96 & $4 \cdot 45$ \\
\hline$\$ 5.00$ & 0.45 & 1.95 & $2 \cdot 24$ & 1.79 & 2.69 & 0.59 & 2.58 & $2 \cdot 96$ & $2 \cdot 37$ & 3.56 \\
\hline$\$ 6.00$ & 0.37 & 1.63 & 1.87 & 1.49 & $2 \cdot 24$ & 0.49 & $2 \cdot 15$ & $2 \cdot 47$ & 1.97 & $2 \cdot 96$ \\
\hline$\$ 7.00$ & 0.32 & 1.39 & 1.60 & 1.28 & 1.92 & 0.42 & 1.84 & $2 \cdot 12$ & 1.69 & 2.54 \\
\hline$\$ 7 \cdot 74$ & 0.29 & $1 \cdot 26$ & 1.45 & $1 \cdot 16$ & $1 \cdot 74$ & 0.38 & 1.67 & 1.91 & 1.53 & $2 \cdot 30$ \\
\hline$\$ 8.00$ & 0.28 & $1 \cdot 22$ & $1 \cdot 40$ & $1 \cdot 12$ & 1.68 & 0.37 & 1.61 & $1 \cdot 85$ & 1.48 & $2 \cdot 22$ \\
\hline$\$ 8.95$ & & & & 1.00 & & & & & & \\
\hline$\$ 9.00$ & 0.25 & 1.08 & 1.25 & 0.99 & 1.50 & 0.33 & 1.43 & 1.65 & 1.31 & 1.98 \\
\hline$\$ 9.76$ & & 1.00 & & & & & & & & \\
\hline$\$ 10.00$ & $0 \cdot 22$ & 0.98 & $1 \cdot 12$ & 0.90 & 1.35 & $0 \cdot 30$ & $1 \cdot 29$ & $1 \cdot 48$ & $1 \cdot 18$ & 1.78 \\
\hline $\begin{array}{l}\$ 11.21 \\
\$ 11.83\end{array}$ & & & $1 \cdot 00$ & & & & & & 1.00 & \\
\hline$\$ 12.00$ & $0 \cdot 19$ & 0.81 & 0.93 & 0.75 & $1 \cdot 12$ & 0.25 & $1 \cdot 07$ & $1 \cdot 23$ & 0.99 & 1.48 \\
\hline $\begin{array}{l}\$ 12.38 \\
\$ 12.89\end{array}$ & $0 \cdot 18$ & 0.79 & 0.91 & 0.72 & $1 \cdot 09$ & $0 \cdot 24$ & $1 \cdot 04$ & $1 \cdot 20$ & 0.96 & $1 \cdot 44$ \\
\hline $\begin{array}{l}\$ 12.89 \\
\$ 13.47\end{array}$ & & & & & $1 \cdot 00$ & & $1 \cdot 00$ & & & \\
\hline$\$ 14.00$ & $0 \cdot 16$ & $0 \cdot 70$ & $0 \cdot 80$ & 0.64 & 0.96 & 0.21 & 0.92 & 1.06 & 0.84 & $1 \cdot 27$ \\
\hline $\begin{array}{l}\$ 14.81 \\
\$ 16.00\end{array}$ & & & & & & & & $1 \cdot 00$ & & \\
\hline $\begin{array}{l}\$ 16.00 \\
\$ 17.79\end{array}$ & $0 \cdot 14$ & 0.61 & 0.70 & 0.56 & $0 \cdot 84$ & 0.18 & 0.81 & 0.93 & 0.74 & $1 \cdot 11$ \\
\hline 19 & . & $\ldots$ & $\ldots$ & $-\ldots$ & - &. & 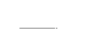 & $\overline{-}$ & $\bar{L}$ & 1.00 \\
\hline
\end{tabular}


Table VI Benefit to cost ratio for prophylactic care of contacts of HIB cases

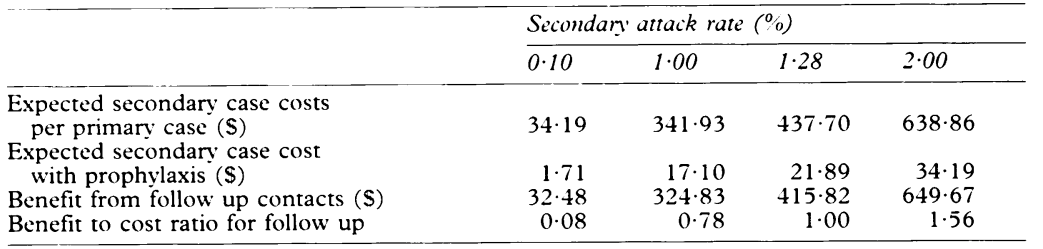

Assumes $95 \%$ efficiency of contact inoculation

Cost per case (excluding child care contacts) $=\$ 34193$
$1.99 / 1$ and $1.65 / 1$ respectively for the four and three dose regimens. Conversely, using a $7 \cdot 5 \%$ discount rate, the benefit to cost ratios fell to $1 \cdot 18 / 1$ and $0 \cdot 97 / 1$ respectively for the four and three dose regimens.

To reach the break even point for society (where benefits equal costs), the costs of the vaccine need to be around $\$ 11 \cdot 21$ and $\$ 14.81$ per dose for the four and three dose regimens respectively (table V). However, if we have overestimated the long term care costs by $30 \%$ then the break even costs fall to $\$ 8.95$ and $\$ 11.83$ per dose respectively for the three and four dose regimens. The vaccine costs need to fall as low as $\$ 2.24$ per dose for health service costs to be covered using four doses, and to $\$ 2.95$ per dose using three doses (table V).

The imposition of a user fee for the HIB vaccine, in addition to the current $\$ 50$ charge levied for all current childhood vaccinations and developmental check ups carried out by the neighbourhood family health centres, might enable the health services to fund the HIB project. While improving the health service benefit to cost ratio, however, this would have no effect on the "social" benefit to cost ratio, as the user charge is merely a transfer payment from the general population to the Ministry of Health.

The break even point for antibiotic prophylaxis of contacts occurs where the secondary attack rate is $1 \cdot 28 \%$. Since the true secondary attack rate is unknown in Israel, stopping prophylactic care for contacts cannot be recommended. In addition, prophylaxis of contacts serves to lower the considerable anxiety generated in parents and neighbours of children who were in close contact with a child suffering from HIB.

Our calculations did not attribute any monetary valuation to the following additional benefits from decreased mortality and morbidity as a result of an HIB innoculation programme:

(i) The lessening of parental anxiety over HIB;

(ii) Reduced pain, worry, or grief as a result of a child contracting HIB.

(iii) Reduction in work absences (as no data were available) in connection with HIB cases which required special education and/or long term institutional care;

(iv) Increase in external benefits that accrue to individuals who feel pleased that people in the society they live in are free from the risk of contracting HIB, not only because they cannot catch HIB themselves (egoistical externality), but also because they care about the health of their fellow citizens (altruistic externality); and

(v) The benefits that some members of the medical comunity will feel because Israel will be providing vaccinations against HIB like other western developed countries instead of being grouped with the developing countries who do not provide their chidren with HIB vaccinations.

The herd immunity effect ${ }^{6} 8303738$ generated by a widespread national HIB vaccination campaign will provide external benefits to children who did not receive the HIB inoculation. The resultant efficiency of the programme over and above the expected from the vaccine efficacy assumptions of our model give us downwardly biased benefit to cost ratios.

In the absence of other projects with higher benefit to cost ratios, Israel should start to provide a nationwide vaccination programme against HIB since the monetary benefits to society of such a programme will exceed the costs to society, assuming a vaccine price of $\$ 11.21$ is achieved in negotiations with the pharmaceutical companies.

A barrier to provision might occur, however, if the Ministry of Health were to take a narrow view of the benefits of the programme and consider only the benefits to the health services alone. The net cost to the health services alone of preventing a child and its parents suffering pain, worry, or grief as a result of contracting HIB is $\$ 16516$. The net cost to the health services per year of human life saved from HIB is $\$ 11382$. Failure to institute a nationwide HIB vaccination programme for infants would contradict our ethical heritage as expressed in the Talmudic maxim that "He who saves a single life, it is as if he has saved the whole world". 39

\section{Addendum}

In January 1993, the Ministry of Health's Infectious Disease Committee unanimously voted for the introduction of a routine neonatal HIB vaccination.

The authors acknowledge the assistance of Alan Greenberg, Chief Pharmacist of Sharei Zedek Hospital, Jerusalem in providing help with pharmaceutical costs and to Anita Bashi, Nurse Epidemiologist of Jerusalem District Health Office in providing data on follow up of contacts.

1 Dagan R and the Israeli Pediatric Bacteremia and Meningitis Group. A two-year propective nationwide study to Group. A two-year propective nationwide study to determine the epidemiology and impact of invasive
childhood Haemophilus influenzae type b infection in Israel. Clinical Infectious Diseases 1992; 15: 720-5.

2 Ministry of Health, Israel. Monthly Epidemiological; Bulletin 1992; 27, 1: 21-4

3 Black SB, Shinefield HR, Fireman B, Hiatt R, Polen M Vittinghoff $E$ and the Northern California Kaiser Permanente Vaccine Study Centre Pediatrics Group. Efficacy in infancy of oligosaccharide conjugate Haemophilus influenzae type $b$ (HbOC) vaccine in a United States population of 61,080 children. Pediatr Infect Dis $\mathscr{F}$ 1991; 10: 97-104.

4 Fritzell B, Plotkin S. Efficacy and safety of a Haemophilus influenzae type $\mathrm{b}$ capsular polysaccharide-tetanus protein conjugate vaccine. 7 Pediatr 1992; 121: 355-62.

5 Santosham M, Rivin B, Wolff $M$, et al. Prevention of Haemophilus influenzae type $b$ infections in Apache and Haemophilus influenzae type b infections in Apache and

Navajo children. F Infect Dis 1992; 165 (suppl I): S144-51 Peltola H, Kilpi T, Antilla M. Rapid disappearance of Haemophilus influenzae type $b$ meningitis after routine chidlhood immunisat

7 Peltola H, Eskola J, Kayhty $\mathrm{H}$, et al. Clinical efficacy of the PRP-D va HbOC conjugate vaccines against Haemophilus PRP-D va $\mathrm{HbOC}$ conjugate vaccines against Haemophilu influenzae type b (Hib). Abstract 975. Program and Abstrac of the 32nd Interscience Conference on Antimicrobial Agents and Chemotherapy. Anaheim, California, 1992.

8 Eskola J, Takala AK, Kayhty H, Koskenniemi E, Peltola $\mathrm{H}$, Makela PH. Protection achieved by Haemophilus influenzae type $b$ (Hib) conjugate vaccines is better than expected on the basis of efficacy trials. Abstract 979. Program and Abstracts of the 32nd Interscience Conference on Antimicrobial Agents and Chemotherapy. Anaheim California, 1992

9 Slater PE, Roitman M, Costin C. Epidemiology of Haemophilus influenzae type b meningitis in Israel 1981 90. Public Health Rev 1991; 18: 307-17. 
10 Ginsberg GM, Shouval D. Cost-benefit analysis of a nationwide neonatal inoculation programme against Community Health 1992; 46: 587-94.

11 Tulchinsky TH, Ginsberg GM, Abed Y, et al. Measles control in developing and developed countries: the case for a two-dose policy. Bull World Health Organ 1993; 71;1: 93-103.

12 Hay JW, Daum RS. Cost-benefit analysis of Haemophilus influenzae type $b$ prevention: conjugate vaccination at influenzae type $\mathrm{b}$ prevention. conjugate vaccination a

13 Cochi SL, Broome CV, Hightower AW. Immunization of US children with Haemophilus influenzae type b US children with Haemophilus influenzae type $b$ polysaccharide vaccine. A cost-effecteiveness
strategy assessment. $7 A M A$ 1985; 253: 521-9.

14 Hay JW, Daum RS. Cost-benefit analysis of two strategies for prevention of haemophilus influenzae Type $b$ infection Pediatrics 1987; 80: 319-29.

15 West DJ, Margolis HS. Prevention of hepatitis B virus infection in the United States: a pediatric perspective. Pediatr Infect Dis $\mathcal{7} 1992 ; 11: 866-74$.

16 Ginsberg GM, Tulchinsky TH. Cost-benefits analysis of a second measles inoculation of children. In: E Kurstak ed. Measles and poliomyelitus - vaccines and immunization. Wein, Measles and poliomyelitus-vaccines and immuniza

17 Central Bureau of Statistics. Statistical abstract of Israel 1992 No 42, Jerusalem: Central Bureau of Statistics, 1992.

18 Black SB, Shinefield HR, Lampert D, et al and the Northern California Kaiser Permanente Vaccine Study Centre Periatrics group. Safety and immunogenicity of oligosaccharide conjugate Haemophilus influenzae type b (HbOC) vaccine in infancy. Pediatr Infect Dis $\mathcal{F} 1991 ; 10$ $92-6$.

19 Ginsberg GM, Berger S, Shouval D. Cost-benefit analysis of a nationwide inoculation programme against hepatitis B in
an area of intermediate endemicity. Bull World Health Organ an area of intermediate

$20 \mathrm{Zmora}$ I. Cost of hospitalization in the Soroka Medical Center. Beer Sheva: Ben Gurion University of the Negev Department of Health, Welfare Economics, and Administration, 1992, Working Paper 82-2.

21 Ginsberg GM. Cost-effectivenes analysis, cost-benefit analysis and the value of life in health care and prevention. In: U Laaser et al eds Costs and benefits in health care and prevention. Berlin: Springer-Verlag 1990; 6-19.

22 Taylor HG, Mills EL, Ciampi A, et al. ????? New Engl f Med 1990; 323: $1657-63$.

23 Ginsberg GM, Silverberg DS. Cost-benefit analysis of the use of crash helmets by bicyclists in Israel. Am $\mathcal{F}$ Pub Health 1992.

24 Feigin RD, Stechenberg BW, Chang MJ, et al. Prospective evaluation of treatment of haemophilus meningitis. $\mathscr{F}$ Pediatr 1976; 88: 542-8.

25 Dodge PR, Swartz MN. Bacterial meningitis-a review of selected aspects: II. special neurological problems, postcorrelations. New Engl f Med 1965; 272: 1003-10.
26 Ferry PC, Culbertson JL, Cooper JA, et al. Sequelae of Haemophilus influenzae meningitis. In: Sell SH, Wright PF eds. Haemophilus influenzae. New York: Elsevier Science eds. Haemophilus influenzae.

27 Sell SHW, Merill RE, Doyne EO, et al. Long-term sequelae of Haemophilus influenzae meningitis. Pediatrics 1972; 49: of Haem $206-17$.

28 Sproles ET III, Azerrad J, Williamson C, et al. Meningitis due to Haemophilus influenzae: long-term sequelae. $\mathcal{F}$ Pediatr 1969; 75: 782-8.

29 Band JD, Fraser DW, Ajello G, et al. Prevention of Haemophilus influenzae type b disease. $\mathscr{f} A M A 1984 ; 251$ 2381-6.

30 Granoff DM, Daum RS, Bois EG, et al. Effect of rifampin chemoprophylaxis on carriage eradication and new acquisition of Haemophilus influenzae type b in contacts. Pediatrics 1985; 76: 537-42.

31 Barbour ML, Booy B, Crook DW, et al. Haemophilus influenzae type b: carriage and immunity four years after conjugate vaccination. Abstract 978. Program and Abstracts of the 32nd Interscience Conference on Antimicrobial Agents and Chemotherapoy. Anaheim, California, 1992; 273.

32 Committe on Infectious Diseases. Haemophilus influenzae type b conjugate vaccines: recommendations for immunizations of infants and children 2 months of age and immunizations of infants and children 2 months of age and older: update. Supplement to Report of Committee of Infectious Diseases, 22nd

33 Daum RS, Granoff DM, Gilsdorf J, et al. $\mathrm{H}$ influenzae type b infections in day-care attendees: implications for management. Rev Infect Dis 1986; 8: 558-67.

34 Immunization Practices Advisory Committee. Haemophilus $b$ conjugate vaccines for prevention of haemophilus influenzae type $b$ disease among infants and children two months of age and older. Recommendations of the Immunization Practices Advisory Committe (ACIP). MMWR 1991; 40: RR-1; 1-7.

35 Desgrandchamps D, Schmid R, Kabus K, Shubiger G. Evaluation of the clinical efficacy of the PRP-D haemophilus influenzae type b conjugate vaccine. Abstract 1728. Programe and Abstracts of the 32nd Interscience Conference on Antimicrobial Agents and Chemotherapy. Anaheim, California: 1992; 399

36 Lieberman JM, Ward JI. Developments in immunization against Haemophilus influenzae type $b$ (Hib) disease. The against Haemophilus influenzae type $b$ (Hib) disease. The

37 Mohle-Boetani J, Ajello G, Breneman E, et al. Oropharyngeal carriage of haemophilus influenzae type $b$ (Hib) in a heavily vaccinated population of $2-5$ year olds. Program and Abstracts of the 32nd Interscience Conference on Antimicrobial Agents and Chemotherapy. Anaheim, California: 1992; 399

38 Takala AK, Eskola J, Leinonen $M$, et al. Reduction in oropharyngeal carriage of haemophilus influenzae type $b$ (Hib) in children immunized with an Hib conjugate vaccine. 7 Infect Dis 1991; 164: 982-6.

39 The Babylonian Talmud, Sanhedrin 37a. London: The Soncino Press, 1961, 3, 324 . 